\title{
Use of trifluoromethylated pseudoprolines for the design of collagen triple helix containing unusual C(5)-substituted proline surrogates
}

\author{
Keyvan Rahgoshay ${ }^{1}$, Anaïs Terrien ${ }^{2}$, Nathalie Lensen ${ }^{1}$, Thierry Brigaud ${ }^{1}$, Emeric Miclet ${ }^{2}$, Grégory Chaume \\ ${ }^{1}$ Université de Cergy-Pontoise, France \\ ${ }^{2}$ Sorbonne Université, France
}

https://doi.org/10.17952/35EPS.2018.206

\section{Introduction}

Collagen is the most abundant protein of mammals. This structural protein is omnipresent and represents the major component of the extracellular matrix. Its tertiary structure consists of three individual lefthanded polyproline II helices folded into a right-handed triple helix which is stabilized by inter-strand hydrogen bonds with a single-residue offset.[1] Each strand comprises the repeat of the (Xaa-Yaa-Gly primary sequence where the proline (Pro, $\mathrm{P}$ and the (4R-4-hydroxyproline (Hyp, O are the most prevalent at Xaa and Yaa positions, respectively.[2] Crystal structures of short-length Collagen Model Peptides (CMPs show that Pro and Hyp residues exhibit preferentially C(4-endo and C(4-exo ring pucker, respectively.[3] This alternation has been proposed to be a prerequisite for the formation of the triple helix (TH since it preorganizes the individual strands in a suitable conformation, thereby decreasing the entropic cost. [4] Following these principles, numerous CMPs have been designed using $\mathrm{C}(4$ - and $\mathrm{C}$ (3-substituted proline derivatives. It was shown that these latter allowed the formation of the $\mathrm{TH}$, provided that they satisfactorily mimic the conformational properties of Pro and Hyp and do not interfere with the interstrand H-bonds.[1] However, due to the packed nature of the collagen $\mathrm{TH}$, substituents in the close vicinity of the backbone could be very deleterious for the $\mathrm{TH}$ stability and, to our knowledge, no work in the literature reports on $\mathrm{TH}$ containing $\mathrm{C}$ (5-substituted proline derivatives. Our group has developed the synthesis of the $\mathrm{CF}_{3}$ pseudoprolines $\left(\mathrm{CF}_{3}-\psi\right.$ Pro and their incorporation into peptides.[5] We previously demonstrated that these proline analogues allow one to locally tune the peptide bond geometry, the puckering of the 5-membered ring as well as the $\Phi$ and $\Psi$ dihedral angles. [6] It was found that the diastereoisomers (S)-CF- $\psi$ Pro (tfm $\psi$ P)and (R)$\mathrm{CF}_{3}-\psi$ Pro $(\mathrm{Tfm} \psi \mathrm{P})$ act as good mimics of the Pro and Hyp residues, respectively, by adopting the prerequisite puckering necessary for the formation and stabilization of the collagen PPII triple helix. However, we showed that the replacement of Hyp by Tfm $\psi \mathrm{P}$ at the Yaa position of the Ac-Xaa-Yaa-GlyNHMe collagen triplet model strongly affects the PPII-like conformation and perturbs the puckering alternation.[7] This result was confirmed with the fact that $\mathrm{Tfm} \psi \mathrm{P}^{11}-[\mathrm{POG}]_{7} \mathrm{CMP} 2$ displays a thermal denaturation lowered by $30^{\circ} \mathrm{C}$ compared to the $[\mathrm{POG}]_{7}$ 1.[8] In other hand, we demonstrated that the incorporation of both $\operatorname{tfm} \psi \mathrm{P}$ and $\mathrm{Tfm} \psi \mathrm{P}$ at respectively the Xaa and Yaa position of the Ac-Xaa-Yaa-GlyNHMe collagen triplet model favors the TH conformational requirements.[7] Finally, predictive molecular modeling realized on the [(Pro-Hyp-Gly) - (tfm $\psi \mathrm{P}-\mathrm{Tfm} \psi \mathrm{P}$-Gly2-(Pro-Hyp-Gly6)] CMP shows that the $\mathrm{CF}_{3}$ groups point outside of the TH and do not cause interstrand steric penalties. Here, we propose to assess and compare the stability of a collagen TH bearing both $\operatorname{tfm} \psi \mathrm{P}$ and $\mathrm{Tfm} \psi \mathrm{P}$ in the middle of a $[\mathrm{POG}]_{7}$ sequence.

\section{Results and Discussion}

Because of the lack of nucleophilicity of the amino group and the steric bulkiness of the vicinal $\mathrm{CF}_{3}$-group, the direct incorporation of the $\mathrm{CF}_{3}-\psi$ Pro residues into the $[\mathrm{POG}]_{7}$ sequence via solid-phase peptide synthesis (SPPS)was excluded. Therefore, we planned to incorporate the two $\mathrm{CF}_{3}-\psi$ Pro residues into the fluorinated host-guest CMP tfm $\psi \mathrm{P}^{10}-\mathrm{Tfm}_{\psi} \mathrm{P}^{11}{ }_{-}[\mathrm{POG}]_{7} 3$ using a "ready to use" tripeptide building blocks for SPPS. At this stage, it was anticipated that the use of the Fmoc-tfm $\psi \mathrm{P}-\mathrm{Tfm} \psi \mathrm{P}-\mathrm{Gly}-\mathrm{OH}$ building block would be extremely challenging since we previously reported that a complete epimerization of the $\mathrm{C}(5$ stereocenter of the $\operatorname{tfm} \psi \mathrm{P}$ residue occurred during peptide coupling reactions at its $\mathrm{N}$-terminus, leading exclusively to the $\mathrm{Tfm} \psi \mathrm{P}$ moiety.[5b] However, we observed that $\mathrm{N}$-acylation reactions using non-hindered acyl chlorides preserved the integrity of the (S)-configurationt the $\mathrm{C}(5)$ position of the tfm $\psi \mathrm{P}$.[5a] Therefore, the triplet frame of the building block was shifted and the Gly residue at the N-terminal position was introduced sequentially starting from the bromoacetyl bromide acylating reagent (Scheme 1)As expected, the $\mathrm{N}$-acylation of the tfm $\psi \mathrm{P}$ residue proceeded without epimerization of the $\mathrm{C}(5$ stereocenter. Treatment with sodium azide followed by 
hydrogenation and Fmoc-protection of the corresponding amine afforded the Fmoc-Gly-tfm $\psi \mathrm{P}-\mathrm{OH}$ dipeptide. The latter is then activated as acyl chloride and coupled with the Tfm $\psi \mathrm{P}$ residue. Subsequent hydrogenolysis of the benzyl ester gave the Fmoc-Gly-tfm $\psi \mathrm{P}-\mathrm{Tfm} \psi \mathrm{P}-\mathrm{OH}$ building block as a single diastereomer in large scale.

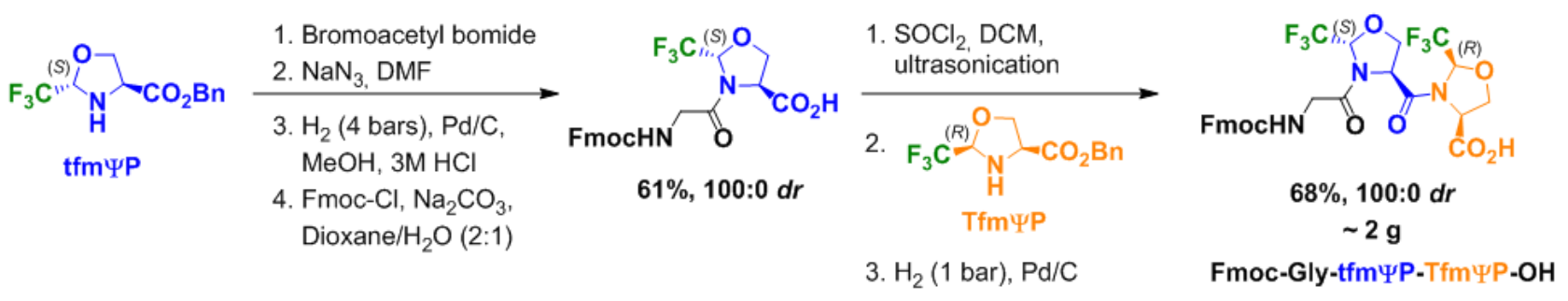

Scheme 1: Synthesis of the "ready to use" Fmoc-Gly-tfm $\psi$ P-Tfm $\psi P$-OH building block

The fluorinated host-guest CMP tfm $\psi \mathrm{P}^{10}-\mathrm{Tfm} \psi \mathrm{P}^{11}{ }_{-}[\mathrm{POG}]_{7} 3$ was prepared on Wang resin by automated SPPS under microwave activation using OxymaPure/DIC as a coupling reagent with similar yield ( 20\%) to those obtained for CMPs 1 and 2 (Scheme 2). This result demonstrates that our $\mathrm{CF}_{3}-\psi$ Pro residues are compatible with SPPS and TFA cleavage. Nonetheless, it should be stressed that the Fmoc removal step after the insertion of the fluorinated building block required the use of Morpholine:DMF (1:3) mixture in the presence of HOBt $(0.1 \mathrm{M})$ to prevent the $\mathrm{tfm} \psi \mathrm{P}-\mathrm{Tfm} \psi \mathrm{P}$ amide bond cleavage.
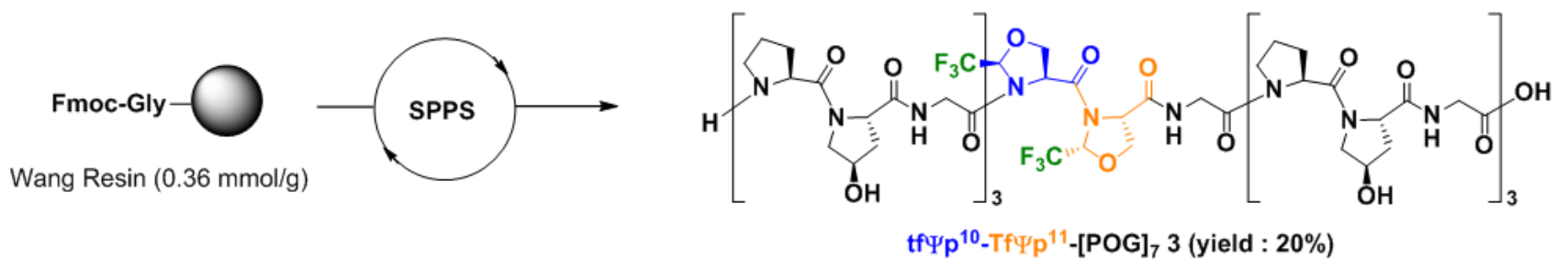

1. Piperidine (16 eq), MW*; 2 . DIC (6 eq), Oxyma pure (6 eq), AAs (6 eq), MW; 3. TFA/TIS/ $\mathrm{H}_{2} \mathrm{O}(95: 2.5: 2.5)$

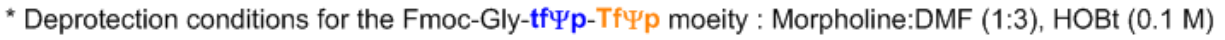

\section{Scheme 2: Synthesis of the fluorinated host-guest CMP 3}

The stability of the triple helix of $\operatorname{tfm} \psi \mathrm{P}^{10}-\mathrm{Tfm} \psi \mathrm{P}^{11}-[\mathrm{POG}]_{7} 3$ was then assessed. CD spectroscopy is the most common analytical method for the determination of collagen TH melting temperatures. At $10 \mathrm{mM}$, the fluorinated CMP 3 exhibits a PPII structuration with the characteristic positive band at $225 \mathrm{~nm}$ on the CD spectrum (Figure 1A). The comparison of the CD spectra of CMPs 1-3 shows that the non-fluorinated CMP 1 displays the higher $[\theta]$ maximum. Sigmoidal curves $[\theta]=f(T)$ were obtained by increasing the temperature as a result of the thermal denaturation of the collagen TH. CMPs 2 and 3 displayed lower melting temperatures $\left(\mathrm{T}_{\mathrm{m}}\right)$ for the TH compared to the reference $[\mathrm{POG}]_{7} 1$ (Figure 1B). However, CMP 3 displays a $12^{\circ} \mathrm{C}$ higher $\mathrm{T}_{\mathrm{m}}$ value compared to CMP 2, despite the fact that it bears a second $\mathrm{CF}_{3}-\psi$ Pro residue. As mentioned before, it was observed that when incorporated into the Ac-Xaa-Yaa-Gly-NHMe collagen triplet model, a single Tfm $\psi \mathrm{P}$ at the Yaa position strongly affects the puckering of the $\mathrm{Xaa}=\mathrm{Pro}$ residue, while when $\mathrm{Xaa}=\mathrm{tfm} \psi \mathrm{P}$ and $\mathrm{Yaa}=\mathrm{Tfm} \psi \mathrm{P}$ the puckering alternation required in the TH model was maintained.[7] This result suggests that satisfying the $\mathrm{C}(4)$-endo/C(4)-exo alternation allows a significant increase of the Tm value in TH models incorporating Pro and Hyp analogues. Therefore, the collagen $\mathrm{TH}$ can accommodate large $\mathrm{CF}_{3}$ groups close to the peptide backbone provided that the puckering alternation is correct and that the $\mathrm{CF}_{3}$ groups point outside of the TH. 
A

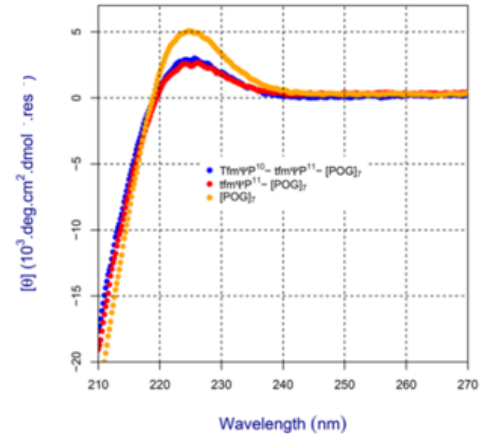

B

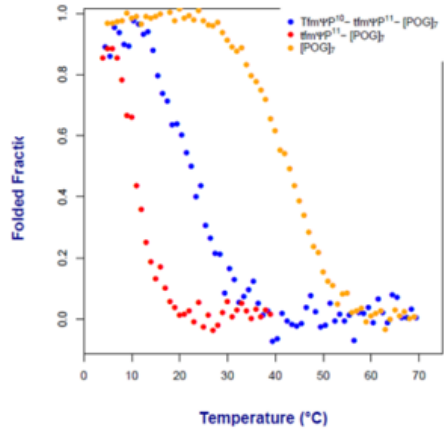

CMP

$[\mathrm{POG}]_{7}$

$\operatorname{Tm}\left({ }^{\circ} \mathrm{C}\right)$

41

tTY $\mathrm{P}^{10} \cdot \mathrm{TPYP} \mathrm{P}^{11} \cdot[\mathrm{POG}]_{7} \quad 23$

$T P \Psi \mathrm{P}^{11} \cdot[\mathrm{POG}]_{7} \quad \mathbf{1 1}$

Figure 1: A. CD spectra of CMPs 1-3 (10 $\mathrm{mM}$, phosphate buffer $\left.(50 \mathrm{mM}), 4^{\circ} \mathrm{C}\right)$ showing the maximum positive band at $225 \mathrm{~nm}$; B. Sigmoidal curves obtained from the thermal denaturation of 1-3 at a heating range of $10^{\circ} \mathrm{C} / \mathrm{h}$.

\section{References}

[1] a) Shoulders, M. D.; Raines, R. T. Annu. Rev. Biochem. 2009, 78, 929; b) Bella, J. Biochem. J. 2016, 473, 1001 .

[2] Ramshaw, J. A. M.; Shah, N. K.; Brodsky, B., J. Struct. Biol. 1998, 122, 86.

[3] a) Vitagliano, L.; Berisio, R.; Mazzarella, L.; Zagari, A. Biopolymers 2001, 58, 459; b) Okuyama, K.; Miyama, K.; Mizuno, K.; Bächinger, H. P. Biopolymers 2012, 97, 607.

[4] Shoulders, M. D.; Satyshur, K. A.; Forest, K. T.; Raines, R. T. Proc. Natl. Acad. Sci. U.S.A. 2010, 107, 559.

[5] a) Chaume, G.; Barbeau, O.; Lesot, P.; Brigaud, T. J. Org. Chem. 2010, 75, 4135; b) Chaume, G.; Simon, J.; Caupène, C.; Lensen, N.; Miclet,. E.; Brigaud, T. J. Org. Chem. 2013, 78, 10144; c) Chaume, G.; Simon, J.; Lensen, N.; Pytkowicz, J.; Brigaud, T.; Miclet, E. J. Org. Chem. 2017, 82, 13602.

[6] Feytens, D.; Chaume, G.; Chassaing, G.; Lavielle, S.; Brigaud, T.; Byun, B. J.; Kang, Y. K.; Miclet, E. J. Phys Chem B. 2012, 116, 4069.

[7] Chaume, G.; Terrien, A.; Renaglia, E.; Marquant, R.; Jacquot, Y.; Brigaud, T.; Miclet, E. Proceedings of the 33rd European Peptide Symposium. Naydenova, E.; Pajpanova, T.; Danalev, D. (Editors), European Peptide Society, 2014, pp 174-175.

[8] Terrien, A.; Rahgoshay, K.; Lensen, N.; Brigaud, T.; Chaume, G.; Miclet, E. Proceedings of the 34th European Peptide Symposium. Beck-Sickinger, A.; Mörl, K.; Bellmann-Sickert, K.; Els-Heindl, S. (Editors), European Peptide Society, 2016, pp 22-23. 